\title{
Comparison of Marginal Fit of Cast Implant Superstructure Pre- and Post-spark Erosion: An in vitro Pilot Study
}

\author{
${ }^{1}$ Shruti Lakhanpal, ${ }^{2}$ Manoj Kumar Sundar, ${ }^{3}$ Shilpa Shetty
}

\begin{abstract}
Objective: To assess and compare the marginal fit of screw retained three unit implant superstructure, before and after spark erosion.
\end{abstract}

Methodology: An experimental model was prepared on which three unit screw retained implant superstructure on two implant analogs (cortex system) was fabricated which was then subjected to spark erosion. Sheffield test (one screw test) was carried out to determine the passivity. Assessment of vertical discrepancy was carried out using stereomicroscopic images of the superstructure and implant analog junction pre- and post-spark erosion with the help of image $\mathrm{J}$ analysis software.

Results: The implant superstructure fabricated with the conventional casting method were fitting actively on the implant analogs indicating a negative Sheffield test. However, following spark erosion passive fit was achieved. The marginal fit of the cast implant superstructure measured from a reference point on the superstructure to the implant analog margin was 4324.56 $\mu \mathrm{m}$ before spark erosion and $4046.57 \mu \mathrm{m}$ after spark erosion.

Conclusion: Spark erosion technology with further research can be used to maximum efficiency to obtain passive fit of implant superstructure.

Keywords: Spark erosion, Electric discharge machining, Passive fit, Cast implant superstructure.

How to cite this article: Lakhanpal S, Sundar MK, Shetty S. Comparison of Marginal Fit of Cast Implant Superstructure Pre- and Post-spark Erosion: An in vitro Pilot Study. Int J Oral Implantol Clin Res 2014;5(3):105-108.

Source of support: Nil

Conflict of interest: None

\section{INTRODUCTION}

Passive fit is simultaneous circumferential contact between the components of the prostheses. A nonpassive fit can transmit undue stresses to the implant and bone and can be detrimental to long-term success of implants. Hence, it

\footnotetext{
${ }^{1}$ Postgraduate Student, ${ }^{2}$ Former Student, ${ }^{3} \mathrm{Head}$

${ }^{1-3}$ Department of Prosthodontics, VS Dental College and Hospital, Bengaluru, Karnataka, India
}

Corresponding Author: Manoj Kumar Sundar, Former Student Department of Prosthodontics, VS Dental College and Hospital Bengaluru, Karnataka, India, Phone: 9789525412, e-mail: manojs87@gmail.com is imperative to limit the stresses induced by prostheses to ensure long-term success of implants. ${ }^{1-4}$

Dental profession is currently experiencing technology explosion. Modern precision laboratory procedures have a profound edge over traditional laboratory procedures in fabricating more ideal and precise restorations. Spark erosion or electric discharge machining is one such procedure. In this procedure, bursts of electricity or sparks are generated between the graphite or copper electrode and the metal work piece to incrementally erode away small amounts of the metal substrate. The entire process takes place in a bath of light oil (dielectric fluid), which simultaneously functions as an insulator, conductor and coolant. Increasing voltage ionizes the fluid between the electrode and the workpiece, establishes an electric current, and produces a rapid buildup of heat approaching temperatures of $12,000^{\circ} \mathrm{C}$. 5,6

Screw retained implant-supported prosthesis has their own pros and cons. In case of multiple unit screw retained prosthesis, passivity is one of the major criteria for ideal force distribution. The passivity can be checked by using Sheffield test (one screw test). ${ }^{7}$ Nonpassive implant and superstructure connection showed varied amounts of marginal gap which paves way for the problems caused by microgaps. Not much of studies have been carried out to assess the marginal discrepancy between the implant superstructure and the implant body owing to its clinical limitations. Hence, this study was undertaken to assess and compare the marginal discrepancy of screw retained threeunit implant superstructure before and after spark erosion.

\section{METHODOLOGY}

\section{Fabrication of Copper Lab Analogs}

Copper lab analogs identical to implant analogs (Cortex system) were fabricated. This was done by making an impression (Fig. 1) of impression post using addition silicone with putty and light body consistencies (Aquasil soft putty and light body), followed by casting of impression with type 4 die stone. Wax-pattern was fabricated over the die. The pattern was then casted with $99.9 \%$ pure copper using the conventional lost wax technique. ${ }^{7}$ The copper replica of the implant analog acts as an electrode (anode or positive potential) and is the negative form of the desired shape to be achieved at the external hex of the abutment (Fig. 2). 


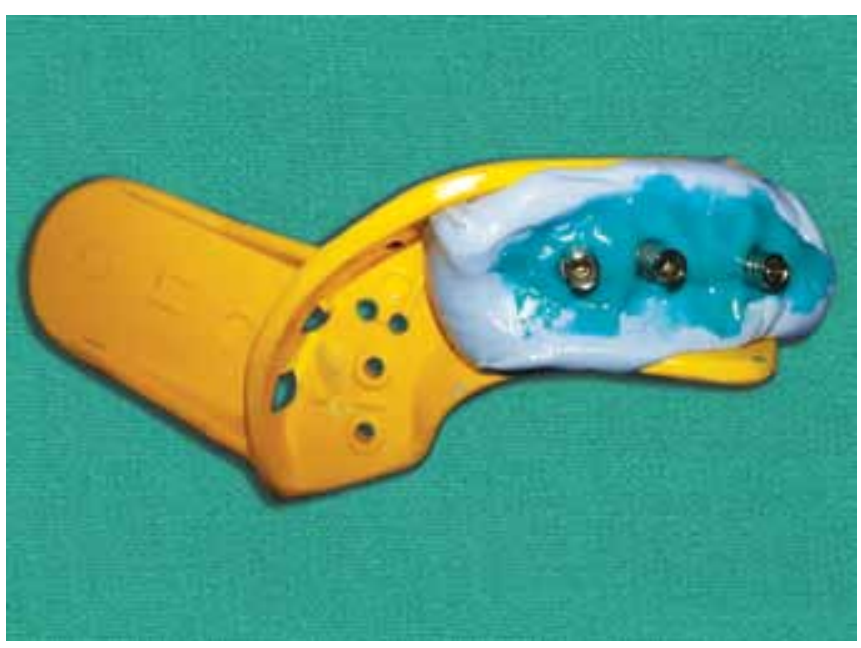

Fig. 1: Impression of the impression posts

\section{Fabrication of Three-unit Screw Retained Implant Superstructure}

Two castable abutments (Cortex-hexed castable abutments) were screwed to two implant analog (Cortex system) and were superimposed on a sheet in such a way that one implant-castable abutment complex was perpendicular to the horizontal reference plane, while the other implant-castable abutment complex was at $15^{\circ}$ angle to the horizontal plane drawn using a protractor, inclined toward the first implantcastable abutment complex (Fig. 3). Pattern resin (GC America) was then used to connect the two castable abutment sleeves and a three unit pattern was fabricated (Fig. 4). The implant analogs were then mounted on a dental stone in order to maintain the orientation and angulation (Fig. 5). Once the dental stone was set and the implant analogs were stabilized the whole three unit resin pattern was then unscrewed and casted. $^{8,9}$

\section{Evaluation of the Marginal Fit Pre-spark Erosion}

Sheffield test was carried out to determine the passivity before subjecting the model to spark erosion. In order to perform this test, the three unit metal superstructure was inserted over the implant analog. The mesial screw was tightened and the distal (angulated implant site) retaining screw was kept out. The measurement of the marginal discrepancy between the implant analog and the abutment superstructure on the distal abutment was measured. For the purpose of standardization, two dots were marked: one on abutment and the other on implant analog to measure the distance between them in micrometers. A stereomicroscope at 40× magnification (Olympus CHi 20) was used and the image of the unscrewed abutment superstructure to the implant analog was captured using a Nikon digital camera mounted to the stereomicroscope. Image J Analysis software was used to measure the distance between the two dots (in

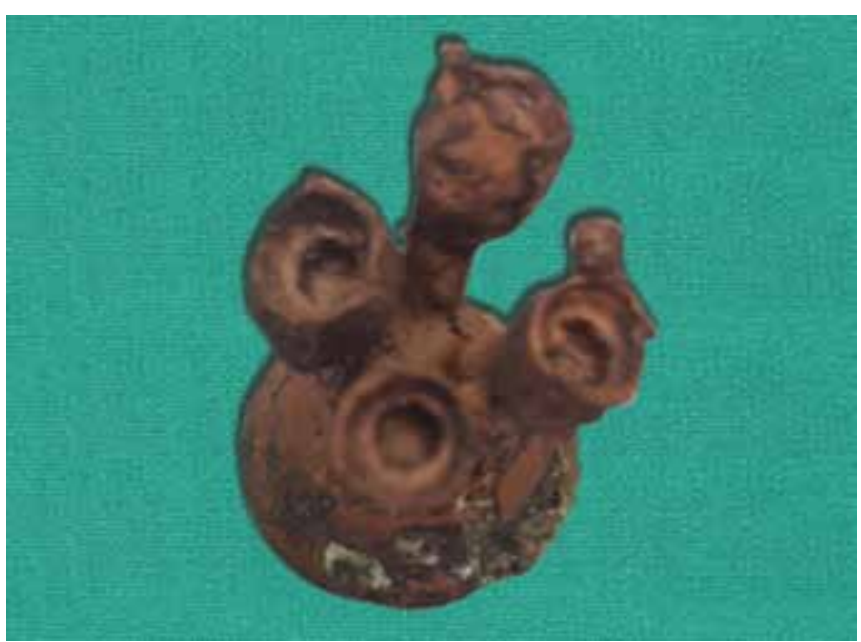

Fig. 2: Copper replica of internal hex connection

\section{Spark Erosion Procedure}

Copper electrodes identical to implant analogs which were casted, were used to replace the implant analogs. The copper implant analogs were placed in the spark erosion unit. The cradle of the machine, which can be moved in all planes, is then aligned over the cast, to maintain the parallelism between superstructure and implant analog. The three unit metal superstructure (the work piece) is attached to the cradle of the machine. The cradle moves the bar toward and away from the electrodes during machining. The framework and the cast are connected to the power source. The dielectric fluid was introduced after the cutting gap was set in the unit. Then, the cradle moves the superstructure onto the copper electrode and the erosion process was initiated. This takes place at the area where the superstructure fits onto the implant abutment. The spark erosion procedure was carried out for 1 minute with a current of $20 \mathrm{~A}^{5,6}$ (Fig. 6).

\section{Evaluation of the Marginal Fit Post-spark Erosion}

The three unit superstructure was again assessed for vertical discrepancy by subjecting it to stereomicroscopic evaluation followed by Image J Analysis software following the same steps as it was carried out pre-spark erosion.

\section{RESULTS}

The three unit implant superstructure fabricated with the conventional method had an active fit over the implant analog indicating a negative Sheffield test.

The marginal discrepancy of the implant superstructure before spark erosion process was $4324.46 \mu \mathrm{m}$ (Fig. 7).

The marginal discrepancy of the implant superstructure following spark erosion procedure was $4046.57 \mu \mathrm{m}$ (Fig. 7).

After spark erosion, the three unit implant superstructure had a passive fit over the implant analog indicating a positive Sheffield test. 


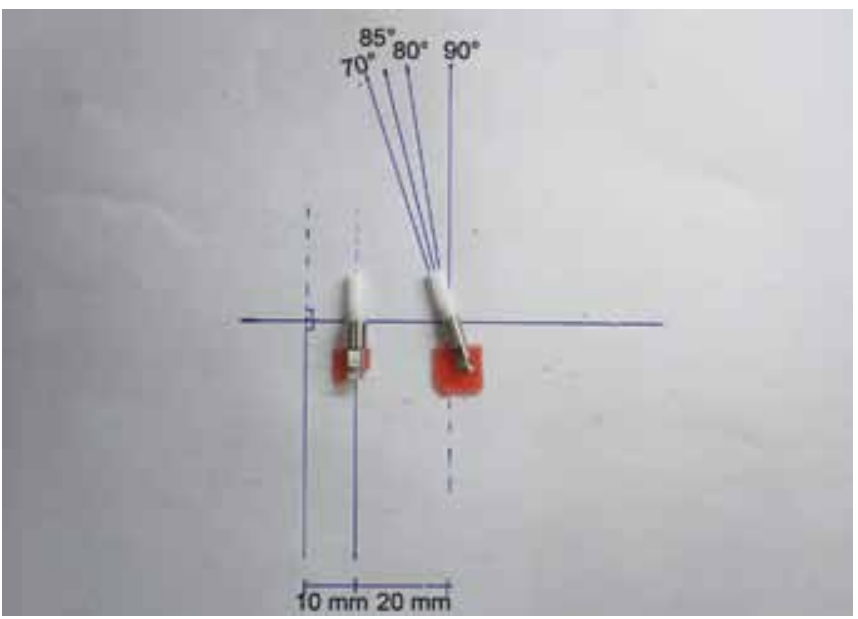

Fig. 3: Fifteen-degree angulation of distal implant-castable abutment complex

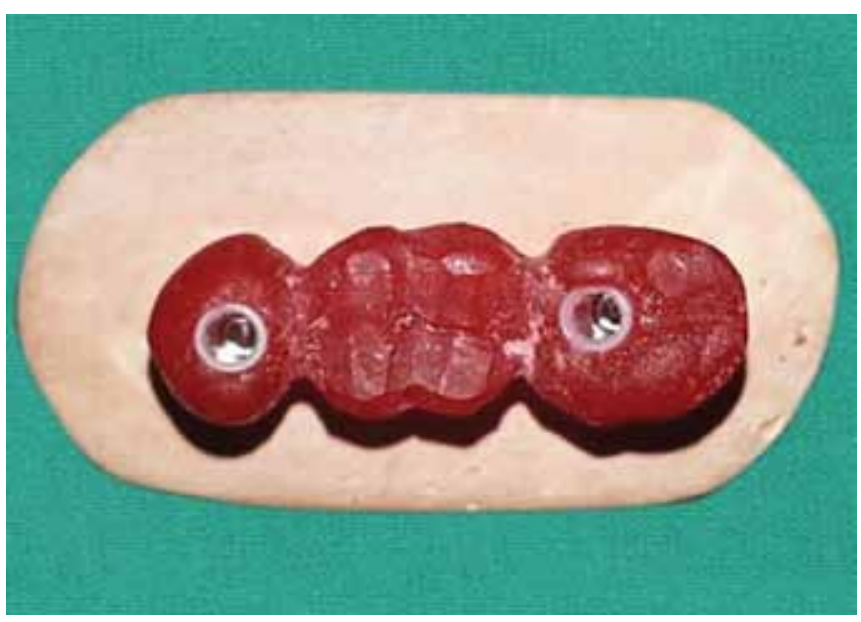

Fig. 5: Implant analog position stabilized with dental stone

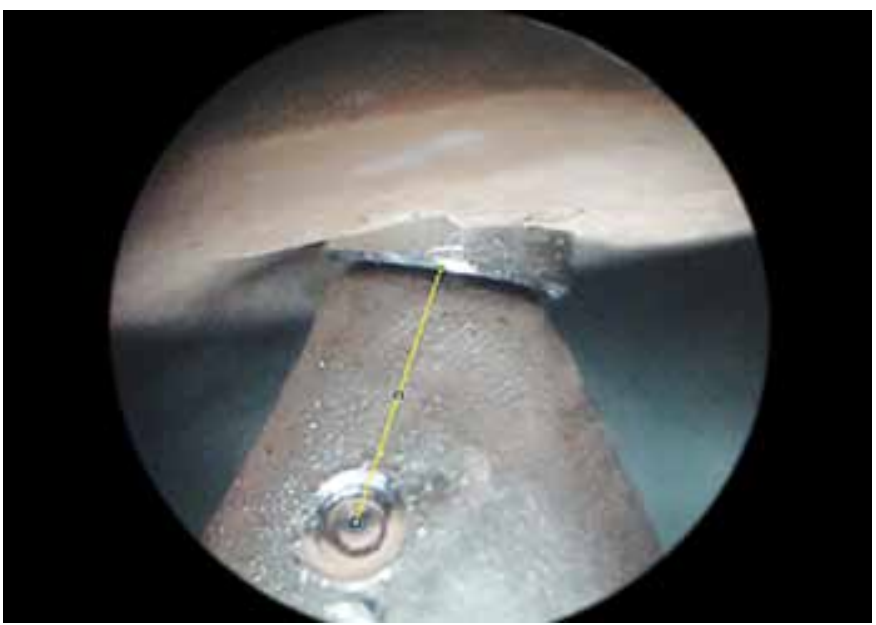

Fig. 7: Analysis of results using Image $\mathrm{J}$ analysis software

\section{DISCUSSION}

There are two techniques for fabricating implant superstructure that are employed in majority of the clinical situations. One involves copy milling followed by laser welding the sections. The other is conventional lost wax technique, which is economical and widely used. If clinical fit of the
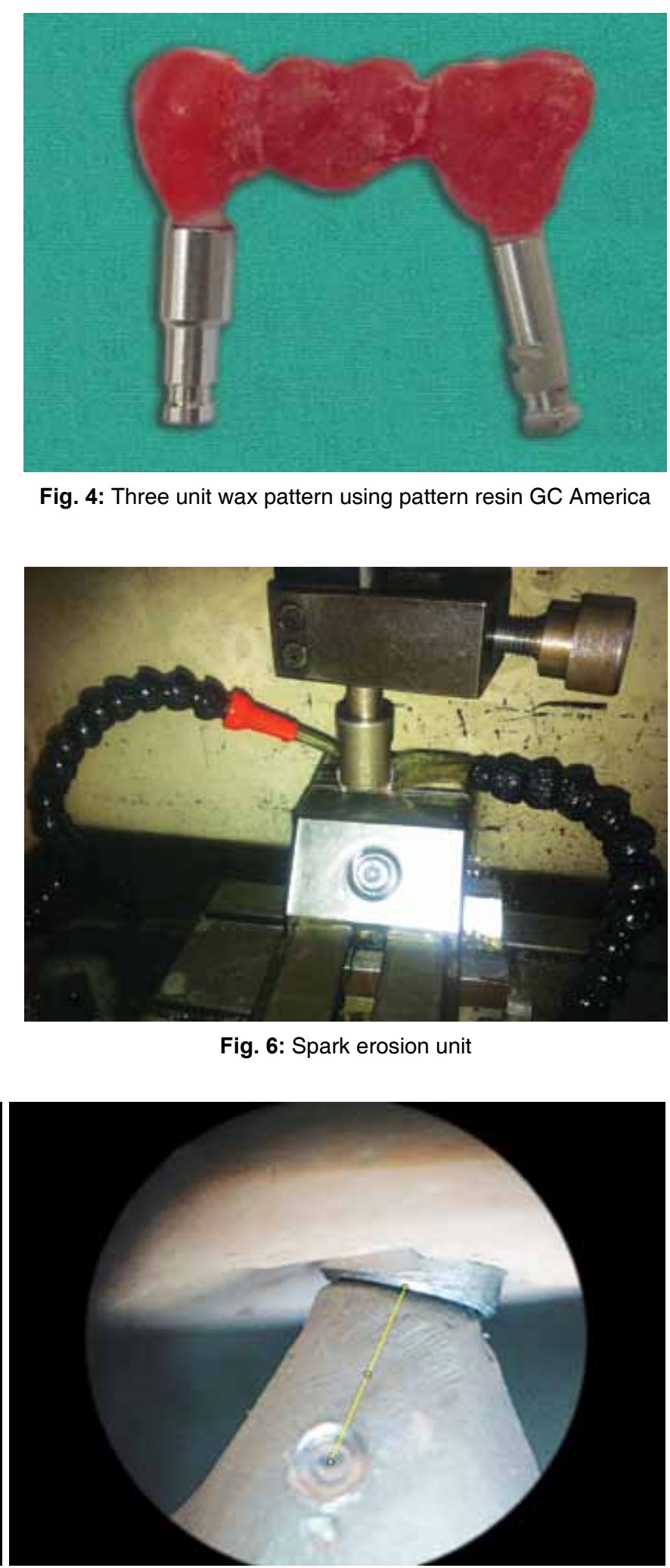

Fig. 4: Three unit wax pattern using pattern resin GC America

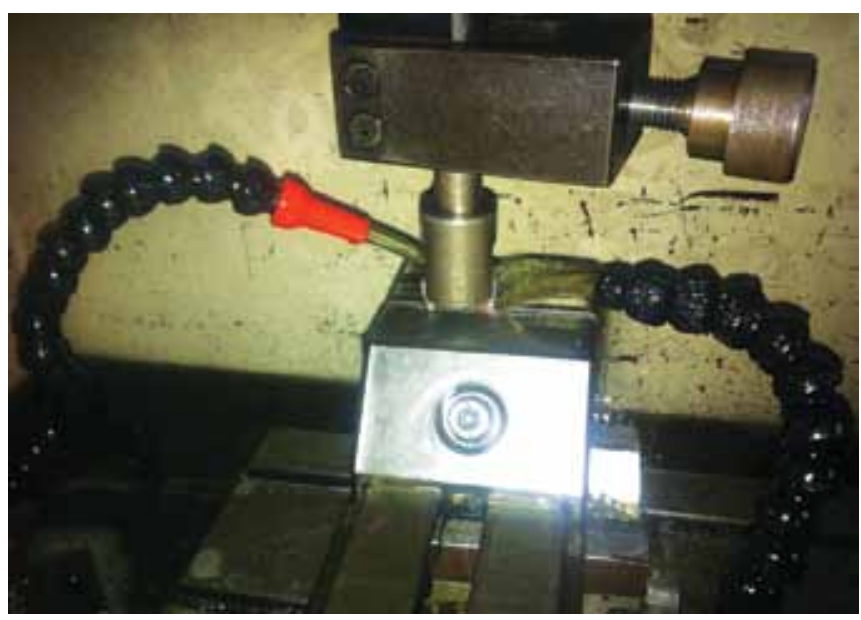

Fig. 6: Spark erosion unit

framework is not obtained then sectioning and soldering is a common strategy, which can be employed to improve the fit of the framework onto implants. These procedures are inaccurate, tedious, sensitive and time consuming. ${ }^{1-4}$

One of the implant analogs was kept at an angulation. This was done in order to mimic a clinical situation of multiple implants, where near parallelism cannot be achieved. 
Copper replica of implant, analog was used as an electrode. It represents the negative form of the desired shape. The copper analogs were separately subjected to spark erosion, in order to maintain parallelism between copper electrode (work piece) and superstructure.

As observed in the study, the vertical discrepancy at implant abutment interface with two reference point one on the superstructure and one on the implant analog margin was $4324.46 \mu \mathrm{m}$. Therefore, a standard method for correcting the misfit ought to be available for use on routine basis. In this study, programed refining of the implant superstructure was done using spark erosion. Following spark erosion the vertical discrepancy was $4046.57 \mu \mathrm{m}$. This shows an improvement in the marginal discrepancy between the two reference points by $277.89 \mu \mathrm{m}$, thus showing the efficacy of spark erosion in improving the marginal discrepancy.

Out of the entire corrective refining procedures available for fabrication of passive implant superstructures, spark erosion offers the following advantages: ${ }^{10}$

- Passive fit of restorations is achieved.

- Complex three-dimensional structures can be shaped regardless of metal hardness since it is a thermal process.

- An extremely thin work piece can be machined without distortion as no mechanical forces are created.

- There is decreased stress on the work piece due to the cooling action of the dielectric fluid.

- Smooth finish of final restoration is ensured.

- There is decreased oxidation of metals during the procedure (especially useful in titanium to porcelain bonding).

- It is rapid, efficient and accurate (within $0.025 \mathrm{~mm}$ ).

- Frameworks with porcelain can be spark eroded without any stress on the porcelain due to the cooling action of the dielectric fluid.

Maintaining exact parallelism between the copper electrode and the superstructure needs to be achieved in case of a distal angulated implants. The machine programming variables, such as, the dielectric amp, voltage and time needs to be evaluated and standardized to measure its effect on machining accuracy of superstructure with spark erosion.
In the present study, reproduction of exact copper replica of the implant analog might not have been achieved owing to the casting shrinkage. ${ }^{11}$ The number of units which was tested for passivity and marginal fit was restricted to a single three unit prosthesis. Further research with larger sample size is required to obtain accurate results. These were some of the known limitations of the study.

\section{CONCLUSION}

Within the limitations of the study, it is concluded that spark erosion technology with further research can be used to maximum efficiency to obtain passivity and hence better marginal adaptation of implant superstructure to the implant.

\section{REFERENCES}

1. Watanabe F, Uno I, Hata Y, Neuendorff G, Kirsch A. Analysis of stress distribution in a screw-retained implant prosthesis. Int J Oral Maxillofac Implants 2000;15(2):209-218.

2. Sahin S, Cehreli MC. The significance of passive framework fit in implant prosthodontics: current status. Implant Dent 2001; 10(2):85-92.

3. Karl M, Winter W, Taylor TD, Heckmann SM. In vitro study on passive fit in implant-supported 5-unit fixed partial dentures. Int J Oral Maxillofac Implants 2004;19(1):30-37.

4. Karl M, Rösch S, Graef F, Taylor TD, Heckmann SM. Strain situation after fixation of three-unit ceramic veneered implant superstructures. Implant Dent 2005;14(2):157-165.

5. Evans DB. Correcting the fit of implant retained restorations by electric discharge machining. J Prosthet Dent 1997;77(2):212-215.

6. Van Roekel NB. Electric discharge machining in dentistry. Int J Prosthodont 1992;5(2):114-121.

7. Rübeling G. New techniques in spark erosion: the solution to an accurately fitting screw-retained implant restoration. Quintessence Int 1999;30(1):38-48.

8. Avila ED, Moraes FD, Castanharo SM, Del Acqua MA, Mollo FA Jr. Effect of splinting in accuracy of two implant impression techniques. J Oral Implantol 2014 Dec;40(6):633-639.

9. Wee AG, Aquilino SA, Scneider RL. Strategies to achieve fit in implant prosthodontics: a review of literature. Int J Prosthodont 1999;12(2):167-178.

10. Liju Jacob Jo. Spark erosion process: an overview. J Dent Implant 2011;1(1):2-6.

11. Anusavice KJ. Phillips' science of dental materials. 11th ed. Phialdelphia: WB Saunders; 2003. p. 565, 584, 585. 